\title{
Trefoil peptide TFF2 (spasmolytic polypeptide) potently accelerates healing and reduces inflammation in a rat model of colitis
}

\author{
C P Tran, G A Cook, N D Yeomans, L Thim, A S Giraud
}

\begin{abstract}
Background-The trefoil peptides are major secretory products of mucus cells of the gastrointestinal tract and show increased expression after inflammatory or ulcerative damage. Recombinant human TFF2 (spasmolytic polypeptide) has been shown to be cytoprotective, and enhances repair in models of gastric injury.

Aims-To test the healing effects of recombinant human (h)TFF 2 in a rat model of chronic colitis.

Methods-Colitis was induced by intracolonic administration of dinitrobenzene sulphonic acid in ethanol. Mucosal repair was quantified macroscopically, microscopically by image analysis of tissue histology, and by measuring myeloperoxidase activity.

Results-Initial validation studies showed that maximal injury and inflammation occurred at the end of the first week after colitis induction (active phase), and that spontaneous healing was complete by eight weeks. Once daily intrarectal application of hTFF2 $(2.5 \mathrm{mg} / \mathrm{kg}$; approximately $0.5 \mathrm{mg} / \mathrm{rat}$ ) for five days after maximal damage had been sustained, reduced both microscopic and macroscopic injury by $80 \%$ and inflammatory index by $50 \%$ compared with vehicle controls. In addition, endogenous concentrations of rat TFF2 and TFF3 (intestinal trefoil factor) were increased in the active phase of colitis and were reduced to basal levels by hTFF 2 treatment.

Conclusions-This study has shown that hTFF2 enhances the rate of colonic epithelial repair, and reduces local inflammation in a rat model of colitis, and suggests that luminal application of trefoil peptides may have therapeutic potential in the treatment of inflammatory bowel disease.

(Gut 1999;44:636-642)
\end{abstract}

Keywords: trefoil peptide; TFF2; spasmolytic polypeptide; colitis; repair

Bagsvaerd, Denmark L Thim

Correspondence to: Associate Professor A S Giraud, University of Melbourne, Department of Medicine at Western Hospital, Footscray 3011 Australia. email:
ag@medicine.unimelb.edu.au

Accepted for publication 17 December 1998

The family of trefoil peptides shares a common structural feature which is one or more copies of the trefoil motif. ${ }^{12}$ This motif consists of a triple loop (trefoil) structure created by three interchain disulphide bonds between six cysteine residues. ${ }^{3}{ }^{4}$ Three mammalian trefoil peptides have been found abundantly with selective distribution in the gastrointestinal tract. TFF1 (pS2), a peptide containing one trefoil motif was first characterised from the MCF-7 human breast cancer cell line ${ }^{5}$ and was later localised in the mucus producing superficial epithelial cells throughout the normal stomach. ${ }^{67}$ Similarly, TFF2 or spasmolytic peptide (SP) with two trefoil motifs, is found throughout the gastric mucosa, but predominantly in the deeper glandular mucous cells of the gastric antrum. ${ }^{78}$ TFF3 or intestinal trefoil factor (ITF) containing a single trefoil domain, is secreted by goblet cells of both the small and large intestine. ${ }^{9}{ }^{10}$ Other related proteins, which contain up to six trefoil motifs, have been found in amphibian skin ${ }^{11}$ and stomach. ${ }^{12}$

In addition to their normal distribution in the digestive tract, trefoil peptide expression is upregulated in conditions such as peptic ulceration and inflammatory bowel disease (IBD).$^{13-15}$ This enhanced expression has been associated with an ulcer associated cell lineage which develops from the glands/crypts adjacent to the ulcer. ${ }^{13}{ }^{16}$ Recent evidence suggests that the upregulation of trefoil expression is prominent during the repair phase after injury, ${ }^{17} 18$ and may be dependent on the increased expression of the epidermal growth factor receptor ligand transforming growth factor $\alpha(\mathrm{TGF}-\alpha){ }^{19}$

The probable reparative functions of the trefoil peptides have been further clarified by recent studies using transgenic animals in which expression of particular trefoil genes has been ablated or augmented. Studies using TFF3 knockout mice revealed a normal phenotype but with increased sensitivity to damaging agents. ${ }^{20}$ TFF1 knockout mice had dysfunctional gastric mucus production; all developed gastric adenomas, and one third neoplasia. ${ }^{21}$ Application of recombinant trefoil peptides has shown that TFF2 and TFF3 are able to promote cell migration in vitro, both alone and in the presence of mucin glycoproteins, ${ }^{22} 23$ as well as protect against gastric injury induced by ethanol or indomethacin in rats. ${ }^{23}$ These preliminary findings, together with their pattern of distribution and co-production with mucus in the gut, suggests that trefoil peptides are involved in mucosal protection and repair.
Abbreviations used in this paper: MPO, myeloperoxidase; TFF2, spasmolytic polypeptide; TFF3, intestinal trefoil factor; IBD, inflammatory bowel disease; SP, spasmolytic peptide; ITF, intestinal trefoil factor; DNBS, dinitrobenzenesulphonic acid; MC, carboxymethylcellulose; MPO, myeloperoxidase; $\mathrm{HTAB}$, hexadecyl trimethylammonium bromide; TGF, transforming growth factor. 
Protocol A

Week

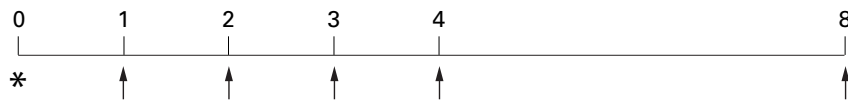

Protocol B

Day

\begin{tabular}{|l|l|l|l|l|l|l|l|l|l|l|l|}
\hline 0 & 1 & 2 & 3 & 4 & 5 & 6 & 7 & 8 & 9 & 10 & 11 \\
\hline$*$ & & & & & & 0 & 0 & 0 & $\bigcirc$ & $\bigcirc$ & $\uparrow$ \\
\hline
\end{tabular}

* Induction of colitis

$\uparrow$ Tissue harvested

Single dose of TFF2

Figure 1 Schematic representation of the time course of DNBS/ethanol induced colitis and resolution (protocol $A$ ), and the TFF2 healing study (protocol B).

While there is evidence for a cytoprotective effect for trefoils in models of gastric damage, the effect of trefoil peptides on colonic injury has not been rigorously explored. In this study, we have quantified the reparative effects of the recombinant human trefoil peptide TFF2 (spasmolytic polypeptide) in the dinitrobenzenesulphonic acid (DNBS)/ethanol model of chronic colitis in the rat. ${ }^{25}$ This model was chosen because it replicates many of the histopathological and clinical features of IBD in humans. Here we report for the first time that recombinant TFF 2 potently accelerates healing, and downregulates inflammation during the active phase of colitis.

\section{Methods}

ANIMALS

Male, Long-Evans Wistar rats (220-280 g; Monash Animal Service, Victoria, Australia) were used in these experiments. The rats were housed in standard cages (four animals per cage) and fed standard laboratory chow and tap water ad libitum.

INDUCTION OF COLITIS

Colitis was induced by a single intracolonic administration of $0.2 \mathrm{ml}$ of $50 \%$ ethanol ( $\mathrm{vol} / \mathrm{vol}$ ) containing DNBS (ICN) at 120 $\mathrm{mg} / \mathrm{ml}$, based on a method described previously. ${ }^{26}$ Briefly, a flexible plastic cannula with an outside diameter of $2 \mathrm{~mm}$ was inserted rectally into a lightly anaesthetised rat so that the tip was $8 \mathrm{~cm}$ proximal to the anus. After delivering the required dose of $\mathrm{DNBS} /$ ethanol solution, the cannula was left in place for about 10 seconds, then gently removed, and the rat returned to the cage. Application method controls (saline) were included for each experiment, in which a separate group of rats received $0.9 \%$ phosphate buffered saline instead of DNBS.

\section{EXPERIMENTAL DESIGN}

Time course of damage and model validation study Rats (four per group) were sacrificed at one, two, three, four, and eight weeks after colitis induction (fig 1; protocol A). Damage and inflammation were assessed as described below.
Healing study

Figure 1 (protocol B) illustrates the course of treatment. Six days after colitis induction (at maximal ulceration and inflammation), rats ( $\mathrm{n}$ $=8$ ) were treated by intrarectal administration of vehicle $(0.2 \mathrm{ml}$ of $1 \%$ carboxymethylcellulose; MC) or human glycosylated recombinant $\mathrm{TFF} 2^{27}$ at $2.5 \mathrm{mg} / \mathrm{ml}$ in $\mathrm{MC}$, once daily for five days. This dose was based on previous in vivo studies of damage repair in the stomach. ${ }^{28}$ All rats were killed 24 hours after the last dose of TFF2 or vehicle.

ASSESSMENT OF MACROSCOPIC DAMAGE

The distal $10 \mathrm{~cm}$ of the rat colon and rectum was excised, opened longitudinally, washed in saline buffer, and pinned out on a wax block. Macroscopic damage was assessed by the scoring system of Wallace and Keenan ${ }^{29}$ which takes into account the area of inflammation and the presence or absence of ulcers. The criteria for assessing macroscopic damage and the numerical rating score were as follows: 0 , no ulcer, no inflammation; 1, no ulcer, local hyperaemia; 2, ulceration without hyperaemia; 3 , ulceration and inflammation at one site only; 4, two or more sites of ulceration and inflammation; 5, ulceration extending more than $2 \mathrm{~cm} ; 6-10$, increment of 1 for each centimetre of ulceration greater than 2 . Randomised tissue samples from the site of DNBS/ethanol application were subsequently excised for histology, and measurement of myeloperoxidase (MPO) activity and endogenous trefoil peptides.

ASSESSMENT OF MICROSCOPIC DAMAGE

Tissue samples taken for histology were fixed overnight in $4 \%$ neutral buffered formalin, processed and sectioned ( $4 \mu \mathrm{m}$ thick), and stained with haematoxylin and eosin. Microscopic damage was quantified by image analysis of stained sections in a blinded fashion as follows: (a) the length of mucosal lesions was measured in arbitrary units and expressed as a ratio of the total length of each section; $(b)$ the cross sectional area of the epithelium, lamina propria, and muscle compartments was quantified in arbitrary units, and expressed as a ratio of the total mucosal area.

MEASUREMENT OF MYELOPEROXIDASE ACTIVITY MPO was extracted and the activity measured using a modified version of the method described by Bradley et al. ${ }^{30}$ Tissue samples were homogenised $(50 \mathrm{mg} / \mathrm{ml})$ in ice cold 50 $\mathrm{mM}$ potassium phosphate buffer $(\mathrm{pH}$ 6.0) containing $0.5 \%$ hexadecyl trimethylammonium bromide (HTAB; Sigma). The homogenate was freeze thawed three times, then centrifuged at $15000 \mathrm{rpm}$ for 20 minutes at $4^{\circ} \mathrm{C}$. A $34 \mu \mathrm{l}$ aliquot of the supernatant was mixed with $986 \mu \mathrm{l}$ of the same phosphate buffer containing $0.167 \mathrm{mg} / \mathrm{ml} \mathrm{O}$-dianisidine dihydrochloride (Sigma) and $0.0005 \%$ hydrogen peroxide, and the change in absorbance at 460 $\mathrm{nm}$ was recorded by a spectrophotometer. One unit of MPO activity was defined as that consuming one nanomole of peroxide per minute at $22^{\circ} \mathrm{C}$. Results were expressed as 


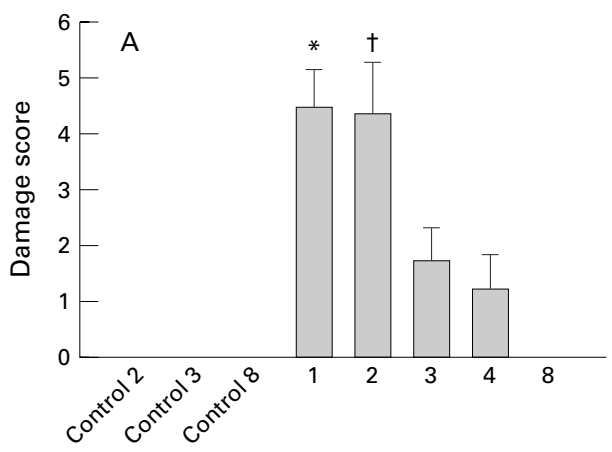

Week

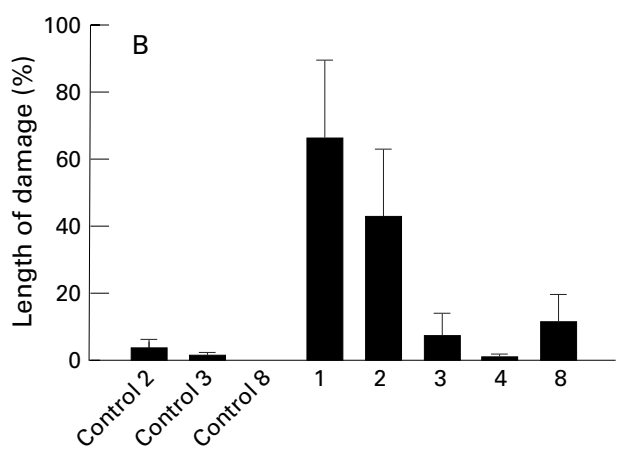

Week

Figure 2 Macroscopic (A; graded point scale) and microscopic (B; ratio of the length of epithelial damage to total section length) damage quantitation in control rats or rats with colitis. ${ }^{\star} p=0.006, t p<0.02$.

$\mathrm{mU} / \mathrm{mg}$ of total protein. Protein concentration was estimated by diluting a $34 \mu \mathrm{l}$ sample into $986 \mu \mathrm{l}$ water and measuring the absorbance at $280 \mathrm{~nm}$, using bovine serum albumin (BSA) as standard. This method was used as the presence of HTAB interfered with the routinely used Bradford protein assay, ${ }^{31}$ based on Coomassie Blue reagent.

QUANTIFICATION OF TFF2 AND TTF3 PROTEIN

The endogenous rat trefoil peptides TFF 2 and $\mathrm{TFF} 3$ were measured by radioimmunoassay as previously described ${ }^{19}$ using region specific polyclonal antibodies in each case. The rat TFF2 assay is specific for the murine peptide and does not cross react with human recombinant TFF2. Total protein concentration was determined using a modified version of the protocol by Bradford et al. ${ }^{31}$

\section{STATISTICAL ANALYSIS}

Results were expressed as mean (SE), with $\mathrm{p}$ value determined by paired $t$ test after analysis of variance (ANOVA). In some cases in which
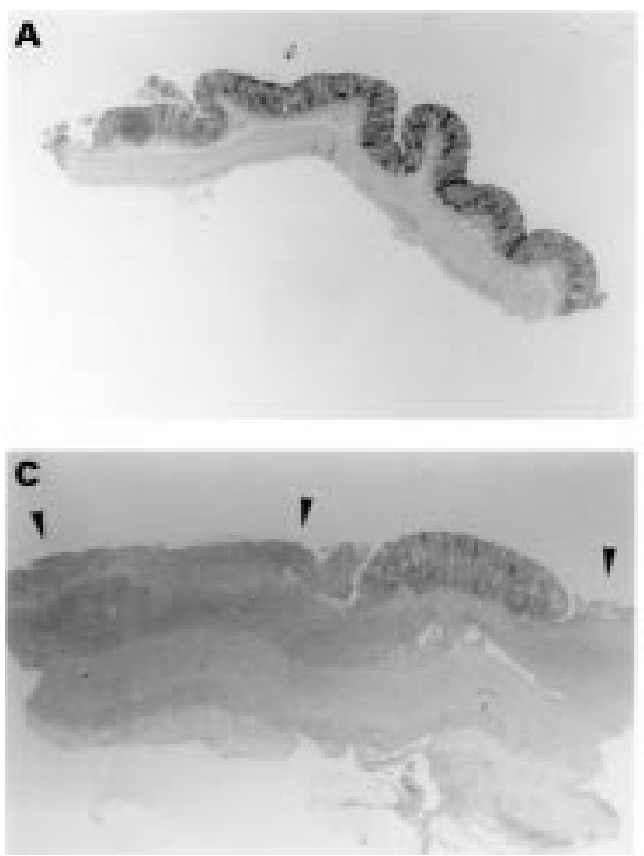

data with wide variances were compared, the Wilcoxon Rank test was used to compare data sets. A p value less than 0.05 was considered to be significant.

\section{Results}

The time course of colitis induction and subsequent repair was quantified in order to validate the method and to determine the time of maximal ulceration and inflammation prior to subsequent experiments in which the healing capacity of TFF2 was assessed.

In the colitis time course study (fig 1), the macroscopic damage score was highest at one and two weeks after induction $(\mathrm{p}<0.02)$, but declined by $50 \%$ at three and four weeks; by eight weeks the mucosal surface appeared visibly normal. Microscopic damage expressed as the ratio of the length of ulcerated epithelium to the total length of the epithelium sectioned (fig 2B), was quantified by image analysis and showed a similar temporal profile after colitis induction to the macroscopic damage score (fig 2A). Thus damage was as high as
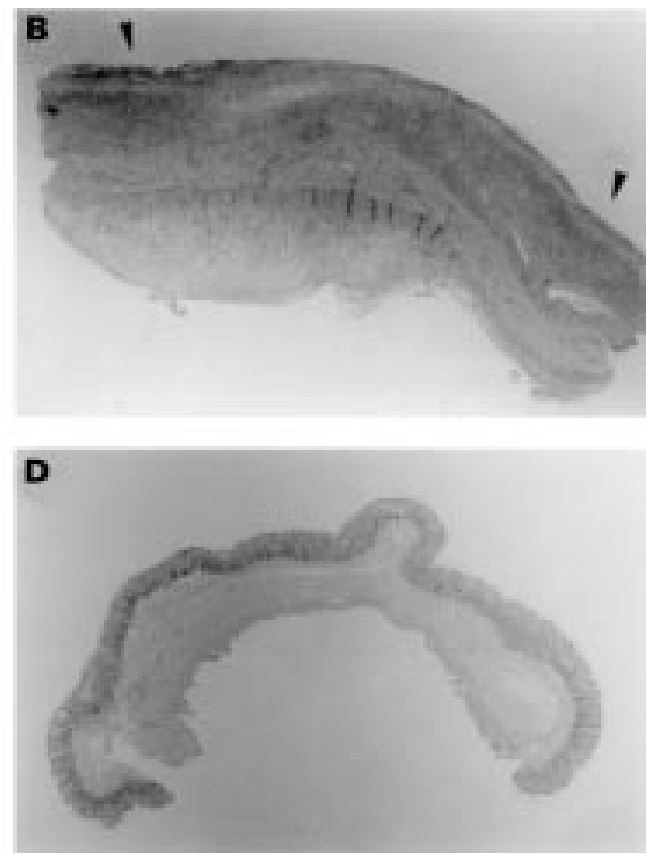

Figure 3 Haematoxylin and eosin stained histological sections of rat colonic mucosa from the time course study. (A) Saline control, (B) one week, (C) two weeks, (D) eight weeks after colitis induction. Ulceration is indicated by arrows. Original magnification $\times 16$. 

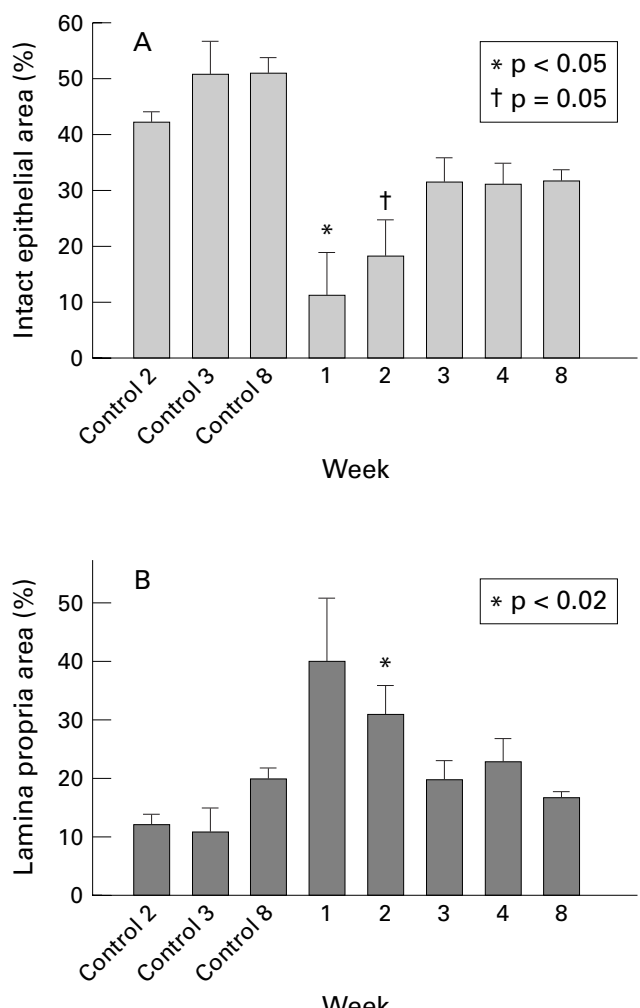

Figure 4 Time course quantitation of the microscopic cross sectional area of mucosal

compartment damage after DNBS/ethanol colitis induction, expressed as a percentage of the total cross sectional area of histological sections of epithelium $(A)$ and lamina propria (B); (C) myeloperoxidase (MPO) activity after DNBS/ethanol colitis.
Week

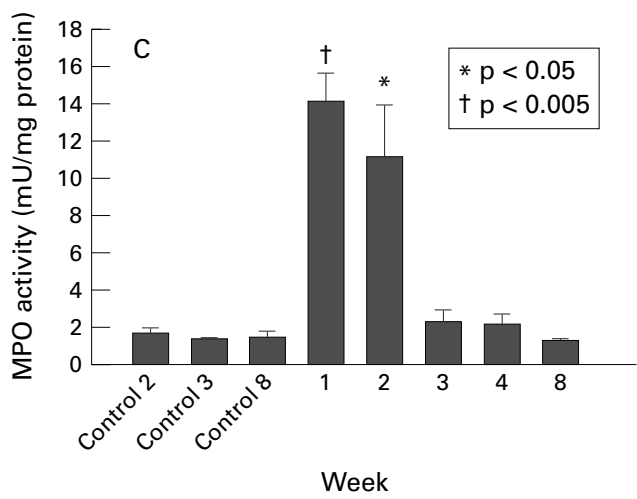

$67(23) \%$ of the epithelium $(\mathrm{p}<0.07$ compared with saline controls) at one week postcolitis induction, falling to $42(20) \%$ at two weeks and less than $10 \%$ at three to eight weeks.

Figure 3 illustrates the time course and extent of colitic injury. In contrast to normal mucosal

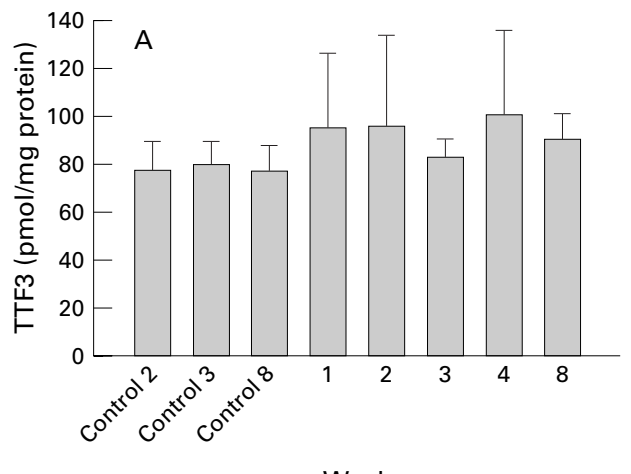

Week organisation in a control rat (fig 3A), at one week postcolitis induction (fig 3B) the epithelium was totally denuded with extensive transmural inflammation. At two weeks (fig 3C) ulceration and inflammation were still obvious; however, by eight weeks the epithelium was healed and no longer inflamed (fig 3D).

Quantitative histology showed that the proportion of the mucosa occupied by intact epithelium was reduced from 51 (7) \% in the normal control colon to $11(8) \%$ at the time of maximal colitic damage (fig 4A), and had recovered to 32 (3)\% by eight weeks, while the lamina propria compartment increased from 12 (2)\% in controls to $40(11) \%$ at one week and had returned to 17 (1)\% at eight weeks (fig 4B). Together these data suggest that although healing was macroscopically complete two months after colitis induction, the mucosa was thinner and contained above normal numbers of cells associated with the inflammatory response, an observation consistent with that seen in human inflammatory bowel disease.

The notable inflammatory response which accompanies the active phase of colitis during the first two weeks after induction was confirmed by the significant rise in $\mathrm{MPO}$ activity at this time from $1.8(0.2) \mathrm{mU} / \mathrm{mg}$ protein prior to colitis to 14 (2) $\mathrm{mU} / \mathrm{mg}$ at one week, and 11.5 (3) $\mathrm{mU} / \mathrm{mg}$ at two weeks (both $\mathrm{p}<0.05$ ), before falling to normal concentrations $(2.4(0.8) \mathrm{mU} / \mathrm{mg})$ by three weeks (fig 4C).

As endogenous trefoil peptide concentrations have been shown to parallel the time course of repair in the upper gut, local concentrations of TFF2 and TFF3 were quantified after colitis induction and in the subsequent repair phase. Endogenous TFF3 remained unchanged throughout (fig 5A), but TFF2, which has negligible expression in the normal colon, was strongly induced threefold at weeks $1(p=0.003$ compared with control) and $2(\mathrm{p}<0.02)$ before returning to near basal concentrations by week 3 and thereafter (fig 5B).

As the time course study had established that maximal ulceration and inflammation occurred by one week after colitis induction, the effect of intrarectal administration of recombinant TFF2 on the rate of healing was evaluated at that time. Following protocol B (fig 1), colitis

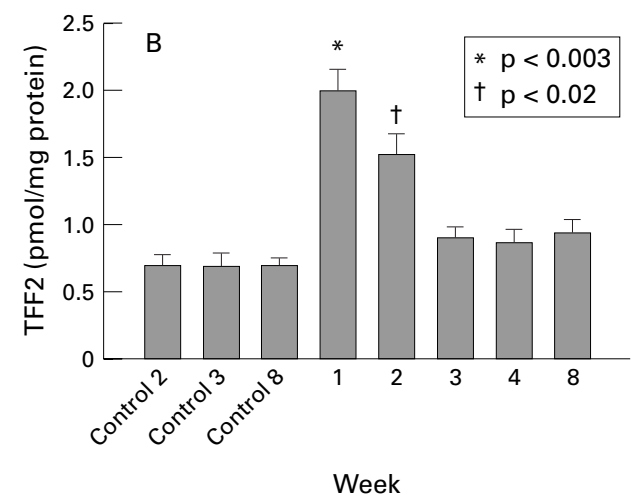

Week

Figure 5 Tissue concentrations of the endogenous trefoil peptides TFF3 (A) and TFF2 (B) after induction of colitis by DNBS/ethanol. 

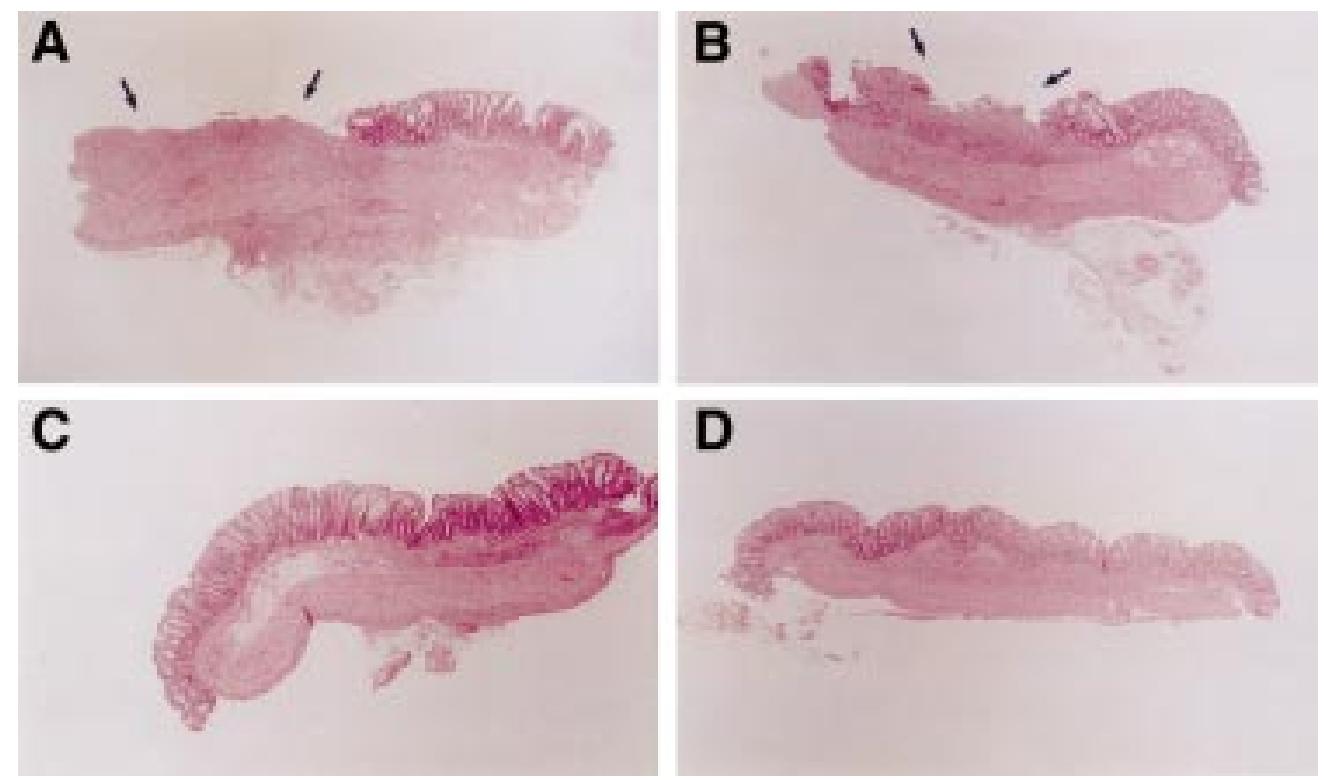

Figure 6 Histological sections of rat colonic mucosa six days after DNBS/ethanol colitis induction and treatment for five days with methylcellulose $(A, B)$ or TFF2 $(C, D)$. Sections stained with haematoxylin and eosin. Areas of erosion and gross inflammatory cell infiltrate are arrowed. Original magnification $\times 16$.

was induced and allowed to develop until day 6 , after which once daily application of TFF2 $(0.2 \mathrm{ml}, 2.5 \mathrm{mg} / \mathrm{kg})$ commenced until day 10 , and rats were sacrificed 24 hours later.

Figure 6 shows representative histological sections from randomised blocks from each of two animals in which colitis had been induced and treated for five days with either the vehicle (methylcellulose, fig 6A,B) or TFF2 (fig $6 \mathrm{C}, \mathrm{D})$. Striking differences were observed in animals treated with TFF2. In active colitis (arrows) frank ulceration was apparent with a total loss of epithelium in some cases. The remaining epithelium was often vacuolated and necrotic, and gross intramural inflammatory infiltrate was apparent in all animals. In contrast, after TFF2 treatment the epithelium was mainly intact, with only occasional small lesions. Branching glands characteristic of epithelial rebuilding were common, and the extent of inflammatory cell penetration (mainly neutrophils and macrophages) was reduced by about $30 \%$ compared with vehicle controls (see fig 8B).

Macroscopic and microscopic assessment of injury in the healing study revealed a highly significant reduction in the damage score (fig $7 \mathrm{~A}, \mathrm{~B})$. The area of the epithelial compartment was decreased from 39 (2)\% (control) to 29

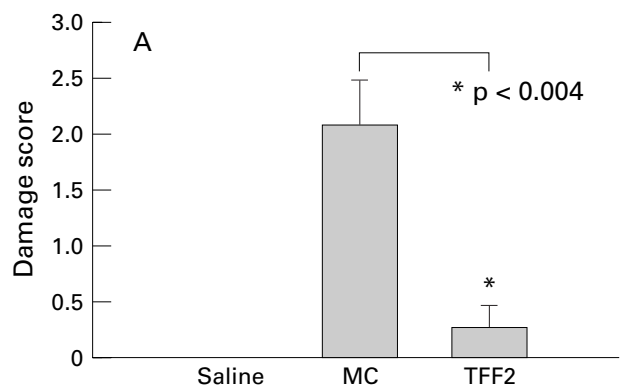

(8) $\%$ of total section area in colitis plus vehicle, but increased to $44(3) \%(p=0.09)$ after TFF2 treatment (fig 8A), while the lamina propria compartment increased in area from $12(1) \%$ in controls to 25 (6)\% in colitis, and was reduced to 17 (2)\% after TFF2 treatment $(p=0.1$; fig $8 \mathrm{~B})$. These trends further underscore the acceleration of reepithelialisation and reduction in inflammatory infiltration induced by $\mathrm{TFF} 2$ seen histologically and in the macroscopic and microscopic damage score. This latter observation was reinforced by the inhibition of MPO activity induced by TFF2, from 15 (2) $\mathrm{mU} / \mathrm{mg}$ protein in animals with colitis plus vehicle to 8 (2) $\mathrm{mU} / \mathrm{mg}$ in those with colitis plus TFF2 ( $p<0.03$; fig $8 \mathrm{C}$ ).

Commensurate with $\mathrm{TFF} 2$ induced repair, endogenous colonic TFF3 tended to increase in the colitis plus vehicle group compared with saline controls $(\mathrm{p}=0.09)$ and had returned to control concentrations after TFF2 treatment $(\mathrm{p}<0.04$; fig 9A). Likewise, colonic TFF2 was significantly higher in the colitis plus vehicle group $(p<0.005)$ compared with saline controls, and was reduced but still elevated above basal concentrations in the TFF2 treated group ( $p<0.07$; fig 9B).

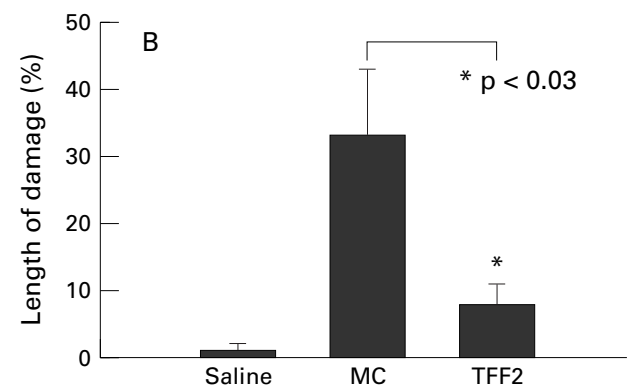

Figure 7 Quantitation of (A) macroscopic colitis score and (B) microscopic cellular damage expressed as a ratio of the length of epithelial damage to total histological section length after DNBS/ethanol colitis and treatment with vehicle or TFF2. MC, methylcellulose. 

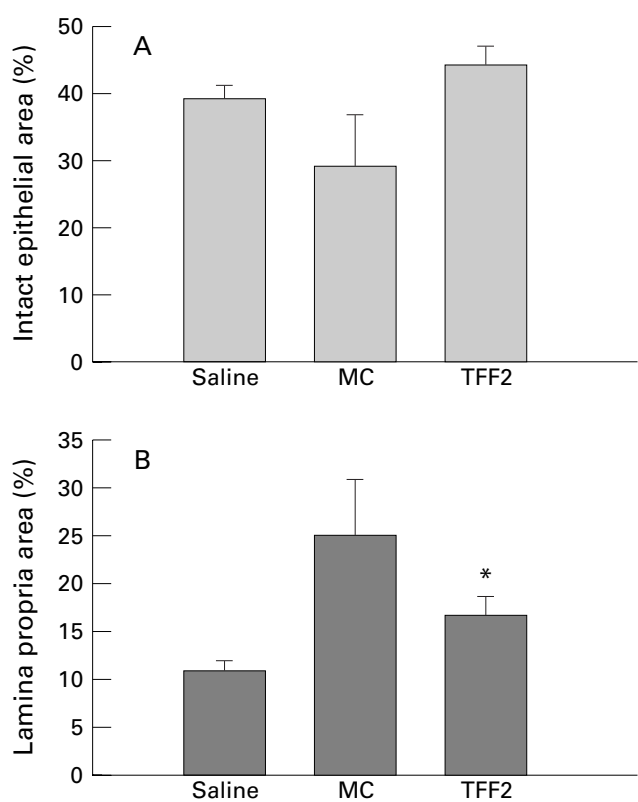

Figure 8 Effect of vehicle (methylcellulose; $M C$ ) or TFF 2 on the microscopic cross sectional area of mucosal compartment damage after

DNBS/ethanol colitis induction, expressed as a percentage of the total cross sectional area of histological sections of epithelium $(A)$ or lamina propria $(B) ;(C)$ mucosal myeloperoxidase (MPO) activity.

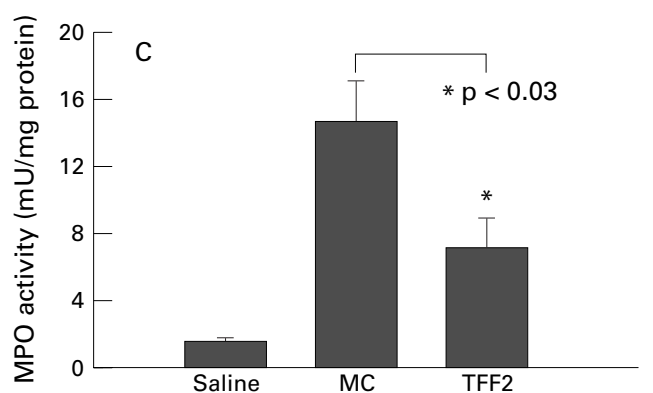

Discussion

It is now well established that the trefoil peptides are cytoprotective $e^{232428} 31$ and are likely to have healing functions in response to a broad range of gastrointestinal damaging agents. This reparative role is supported by the sustained increase in endogenous trefoil peptide concentrations following injury, ${ }^{163}$ and may be accomplished in several ways, with evidence for participation in the very early phase of gastointestinal repair notable by cell migration across the wound site known as restitution, ${ }^{22}$ as well as in the subsequent protracted phase of glandular renewal, notable by cell proliferation and differentiation. ${ }^{16}{ }^{33}$

Previous studies have established that the endogenous trefoil peptides may participate in mucosal healing in IBD. Elevated tissue concentrations of the trefoil peptides TFF1 and TFF3 have been shown in active Crohn's

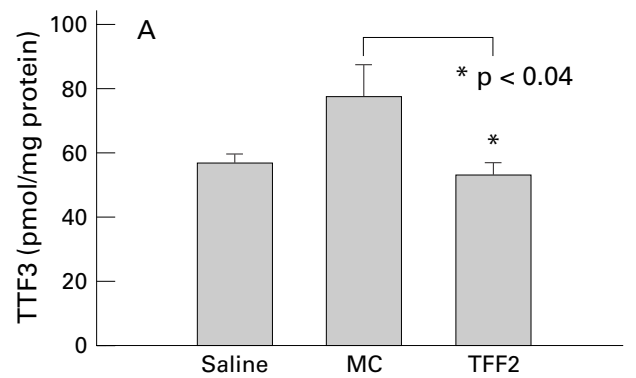

disease ${ }^{15}$ and in an acetic acid model of colitis ${ }^{18}$; in the latter they remained elevated even after macroscopic repair was complete. Although TFF3 knockout mice did not develop spontaneous colitis, they were found to be far more susceptible to colonic ulceration and bleeding in response to ingestion of dextran sulphate than wild type controls, suggesting that local expression of this trefoil peptide at least helped to maintain epithelial integrity. In support of this proposition was the partial rescue of the damaged mucosa in one animal by two luminal applications of recombinant TFF $3 .^{20}$

In this study we have shown that in an established model of colitis, which exhibits damage and repair profiles in common with the human inflammatory bowel diseases ulcerative colitis and Crohn's disease, that luminal application of the trefoil peptide TFF2 (human spasmolytic polypeptide) promotes rapid repair of the epithelium and reduces inflammatory indexes (MPO activity and lamina propria volume) when given in the active (maximally damaging) phase. It is therefore possible that the trefoil peptides reduce the symptoms of colitis by multiple mechanisms, both in accelerating tissue repair, and perhaps by inhibiting inflammatory cell activity or access to the mucosa. Another possibility is that the reduction in inflammation follows as a consequence of the re-establishment of mucosal integrity, as luminal antigens, which initiate the inflammatory response, presumably no longer have epithelial access.

What is the mechanism of action of TFF2 healing in the DNBS/ethanol colitis model? Much circumstantial evidence suggests that the trefoil peptides interact with mucins to augment the barrier function of mucus, which in turn would allow faster repair. This is supported by the presence of trefoils in mucus cells and in the gel lining the colonic epithelium, ${ }^{15}$ the augmentation of trefoil induced cytoprotection by mucins, ${ }^{2324}$ and the synergism between trefoil peptides and mucins in enhancing epithelial barrier function. ${ }^{34}$ Trefoil peptides are also potent motogens and have been shown to accelerate cell migration by colonocytes $^{22}$ and act as chemotaxins for monocytes, ${ }^{35}$ both of which participate in reparatory events following damage in IBD.

Apart from the activity of the exogenously applied TFF2, our results show that endogenous TFF2 is induced in the colon with a time course paralleling that of the ulcerative and inflammatory response after DNBS/ethanol.

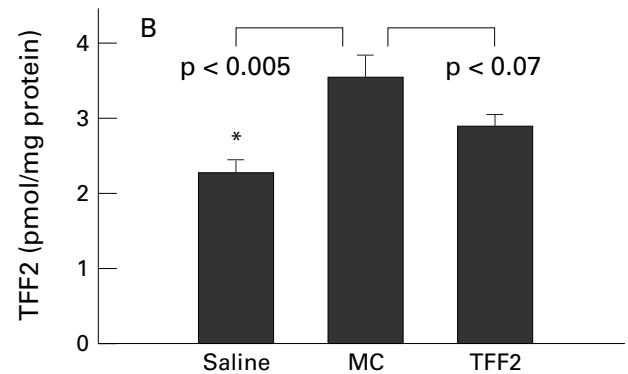

Figure 9 Effect of vehicle (methylcellulose; MC) or TFF2 on endogenous mucosal TFF2 and TFF3 concentrations after DNBS/ethanol colitis induction. 
This was most notable for endogenous TFF2, which was hardly detectable in the normal colon, but which was elevated severalfold in the active phase of colitis, and returned to basal concentrations as healing progressed. These data and results from previous studies ${ }^{18}$ suggest that expression of all three known trefoil peptide genes is increased in rat models of IBD, and that the efficacy in accelerating repair is not restricted to trefoil peptides (TFF3) found only in the colon under basal conditions.

There are several clinical implications which derive from our observations. Firstly, if endogenous trefoil peptide concentrations in the colon can be augmented specifically, particularly in IBD, then the damaging manifestations of the disease may be reduced or eliminated. To date several neurotransmitters and local peptide regulators of mucin gene expression have been shown to stimulate TFF3 expression in vitro $^{36}$; however, whether this response is true for other members of the trefoil peptide family and is sustained in vivo or not has yet to be tested. Secondly, in this IBD model TFF2 is more effective in healing the epithelium after the active colitic damage is maximal than are sulphasalazine, ${ }^{28}{ }^{37}$ prednisolone, ${ }^{37}$ or epidermal growth factor. ${ }^{38}$ It remains to be seen whether or not trefoil application is effective in preventing or reducing the extent of disease relapse, which can be induced in this model by multiple subcutaneous injections of the hapten alone after the initial healing phase is complete $^{39}$; it should be possible to test the efficacy of TFF2 in this regard in future studies.

The results of this study re-emphasise the key role for the trefoil peptides in resolution of epithelial damage of the gastrointestinal tract, and suggest that TFF2 and probably other members of the trefoil peptide family or their derivatives may have potential as future therapeutic agents in the treatment of inflammatory bowel diseases.

This study was supported by project grants funded by the National Health and Medical Research Council of Australia, and Astra Hassle, Sweden. C P Tran was the recipient of a postgraduate scholarship from the University of Melbourne.

1 Thim L. A new family of growth factor-like peptides. 'Trefoil' disulfide loop structures as a common feature in breast cancer associated peptide (pS2), pancreatic spasmolytic polypeptide (PSP), and frog skin peptides (spasmolysins). FEBS Lett 1989;250:85-90.

2 Thim L. Trefoil peptides-from structure to function. Cellular and Molecular Life Sciences 1997;53:888-903.

3 Poulsom R. Trefoil peptides. Bailliere's Clin Gastroenterol 1996;10:113-34.

4 Sands BE, Podolsky DK. The trefoil peptide family. Ann Rev Physiol 1996;58:253-73.

5 Masiakowski P, Breathnach R, Bloch J, et al. Cloning of Masiakowski P, Breathnach R, Bloch J, et al. Cloning of MCF-7 human breast cancer cell line. Nucleic Acids Res 1982;10:7895-903.

6 Rio MC, Bellocq JP, Daniel JY, et al. Breast cancerassociated pS2 protein; synthesis and secretion by normal stomach mucosa. Science 1988;241:705-7.

7 Hanby AM, Poulsom R, Singh S, et al. Spasmolytic polypeptide is a major antral peptide: distribution of the trefoil peptide human spasmolytic polypeptide and ps2 in the stomach. Gastroenterology 1993;105:1110-16.

8 Jeffrey GP, Oates PS, Wang TC, et al. Spasmolytic polypeptide: a trefoil peptide secreted by rat gastric mucous cells. Gastroenterology 1994;106:336-45.

9 Suemori S, Lynch-Devaney K, Podolsky DK. Identification and characterization of rat intestinal trefoil factor; tissue and cell-specific member of the trefoil protein family. Proc Natl Acad Sci USA 1991;88:11017-21.

10 Podolsky DK, Lynch-Devaney K, Stow JL, et al. Identification of human intestinal trefoil factor. Goblet cell-specific tion of human intestinal trefoil factor. Goblet cell-specific expression of a peptide targete
Chem 1993;268:6694-702.
11 Hauser F, Roeben C, Hoffman W. xP2, a new member of the $\mathrm{P}$-domain peptide family of potential growth factors, is synthesised in Xenopus laevis skin. $\mathcal{F}$ Biol Chem 1992;267: 14451-5.

12 Hauser F, Hoffman W. xP1 and xP4. P-domain peptides expressed in Xenopus laevis stomach mucosa. F Biol Chem 1991;266:21306-9.

13 Wright NA, Poulsom R, Stamp GW, et al. Epidermal growth factor (EGF/URO) induces expression of regulatory peptides in damaged human gastrointestinal tissues. $\mathcal{f}$ Pathol 1990;162:279-84.

14 Rio M-C, Chenard M-P, Wolf C, et al. induction of pS2 and hSP genes as markers of mucosal ulceration of the digestive tract. Gastroenterology 1991;100:375-9.

15 Wright NA, Poulsom R, Stamp G, et al. Trefoil peptide gene expression in gastrointestinal epithelial cells in inflammatory bowel disease. Gastroenterology 1993;104:12-20.

16 Alison MR, Chinery R, Poulsom R, et al. Experimental ulceration leads to sequential expression of spasmolytic polypeptide, intestinal trefoil factor, epidermal growth factor and transforming growth factor-alpha messengerRNAs in rat. F Pathol 1995;175:405-14.

17 Tomita $\mathrm{M}$, Itoh $\mathrm{H}$, Ishikawa $\mathrm{N}$, et al. Molecular cloning of mouse intestinal trefoil factor and its expression during goblet cell changes. Biochem f 1995;311:293-7.

8 Itoh $\mathrm{H}$, Tomita $\mathrm{M}$, Uchino $\mathrm{H}$, et al. cDNA cloning of rat $\mathrm{pS} 2$ peptide and expression of trefoil peptides in acetic acid-induced colitis. Biochem f 1996;318:939-44.

19 Cook GA, Yeomans ND, Giraud AS. Temporal expression of trefoil peptides in the TGF- $\alpha$ knockout mouse after gastric ulceration. Am ₹ Physiol 1997;272:G1540-9.

20 Mashimo H, Wu DC, Podolsky DK, et al. Impaired defense of intestinal mucosa in mice lacking intestinal trefoil factor. Science 1996;274:262-5.

21 Lefebvre O, Chenard MP, Masson R, et al. Gastric mucosa abnormalities and tumorigenesis in mice lacking the pS2 trefoil protein. Science 1996;274:259-62.

22 Dignass A, Lynch-Devaney K, Kindon H, et al. Trefoil peptides promote epithelial migration through a TGF- $\beta$ independent pathway. F Clin Invest 1994;94:376-83.

23 Playford RJ, Marchbank T, Chinery R, et al. Human SP is a cytoprotective agent that stimulates cell migration. Gastroenterology 1995;108:108-16.

24 Babyatsky MW, DeBeaumont M, Thim L, et al. Oral trefoil peptides protect against indomethacin-induced gastric injury in rats. Gastroenterology 1996;110:489-97.

25 Wallace JL, Le T, Carter L, et al. Hapten-induced chronic colitis in the rat: alternatives to trinitrobenzene sulfonic acid. F Pharmacol Toxicol Methods 1995;33:237-9.

26 Morris GP, Beck PL, Herridge MS, et al. Hapten-induced model of chronic inflammation and ulceration in the rat. Gastroenterology 1989;96:795-803.

27 Thim L, Norris K, Norris F, et al. Purification and characterization of the trefoil peptide human spasmolytic polypeptide (hSP) produced in yeast. FEBS Lett 1993;318: polypep

28 Cook GA, Yeomans ND, Thim L, et al. Oral spasmolytic polypeptide is cytoprotective against aspirin induced injury in the rat stomach. F Gastroenterol Hepatol 1998;13:363-70.

29 Wallace JL, Keenan CM. An orally active inhibitor of leukotriene synthesis accelerates healing in a rat model of colitis. Am f Physiol 1990;258:G527-34.

30 Bradley PP, Priebat DA, Christensen RD, et al. Measurement of cutaneous inflammation: estimation of neutrophil content with an enzyme marker. F Invest Dermatol 1982;78:206-9.

31 Bradford M. A rapid and sensitive method for the quantitation of microgram quantities of protein utilizing the principle of protein dye binding. Anal Biochem 1976;72:248-54.

32 McKenzie C, Marchbank T, Playford R, et al. Pancreatic spasmolytic polypeptide protects the gastric mucosa but does not inhibit acid secretion or motility. Am f Physiol 1997;273:G112-17.

33 Taupin DR, Cook GA, Yeomans ND, et al. Increased trefoil peptide expression occurs late in the healing phase in a model of gastric ulceration in the rat [abstract]. Gastroenterology 1994;106:A195.

34 Kindon H, Pothoulakis C, Thim L, et al. Trefoil peptide protection of intestinal epithelial barrier function: cooperative interaction with mucin glycoprotein. Gastroenterology 1995;109:516-23.

35 Cook GA, Yeomans ND, Giraud AS. Trefoil peptides show rapid cytoprotective effects against aspirin damage and may also regulate the inflammatory response by stimulating monocyte migration. I Gastroenterol Hepatol 1997;12 (suppl 1):A207.

36 Ogata H, Podolsky DK. Trefoil peptide expression and secretion is regulated by neuropeptides and acetylcholine. Am ₹ Physiol 1996;273:G348-54.

37 Broughton-Smith NK, Wallace JL, Morris GP, et al. The effect of anti-inflammatory drugs on eicosanoid formation in a chronic model of inflammatory bowel disease in the rat. Br F Pharmacol 1988;94:65-72.

38 Procaccino F, Reinshagen M, Hoffmann P, et al. Protective effect of epidermal growth factor in an experimental model of colitis in the rat. Gastroenterology 1994;107:12-17.

39 Appleyard CB, Wallace JL. Re-activation of hapten-induced colitis and its prevention by anti-inflammatory drugs. $A m \mathcal{F}$ Physiol 1995;269:G119-25. 